\title{
Efficacy of virtual reality-based intervention on balance and mobility disorders post-stroke: a scoping review
}

\author{
Anuja Darekar ${ }^{1,2^{*}}$, Bradford J McFadyen ${ }^{3}$, Anouk Lamontagne ${ }^{1,2}$ and Joyce Fung ${ }^{1,2}$
}

\begin{abstract}
Rehabilitation interventions involving virtual reality (VR) technology have been developed for the promotion of functional independence post stroke. A scoping review was performed to examine the efficacy of VR-based interventions on balance and mobility disorders post stroke. Twenty-four articles in the English language examining VR game-based interventions and outcomes directed at balance and mobility disorders were included. Various VR systems (customized and commercially available) were used as rehabilitation tools. Outcome measures included laboratory and clinical measures of balance and gait. Outcome measures of dynamic balance showed significant improvements following VR-based interventions as compared to other interventions. Further, it was observed that VR-based intervention may have favorable effects in improving walking speed and the ability to deal with environmental challenges, which may also facilitate independent community ambulation. VR-based therapy thus has the potential to be a useful tool for balance and gait training for stroke rehabilitation. Utilization of motor learning principles related to task-related training may have been an important factor leading to positive results. Other principles such as repetition, feedback etc. were used in studies but were not explored explicitly and may need to be investigated to further improve the strength of results. Lastly, robust study designs with appropriate attention towards the intensity and dose-response aspects of VR training, clear study objectives and suitable outcomes would further aid in determining evidence-based efficacy for VR game-based interventions in the future.
\end{abstract}

Keywords: Balance deficits, Cerebrovascular accident, Gait, Gait retraining, Game-based rehabilitation, Physiotherapy, Posture, Rehabilitation, Stroke, Virtual reality

\section{Introduction}

Although the length of in-hospital stay following an episode of stroke has consistently decreased [1-3], many individuals return home with residual deficits. Balance and gait deficits are commonly observed in this population, leading to reduced ambulatory activity [4], limitations in activities of daily living and community participation $[5,6]$, physical inactivity and subsequent deterioration in quality of life $[7,8]$. Therefore, rehabilitation efforts geared towards improving balance and mobility are important to facilitate functional independence and optimize community ambulation and participation. One

\footnotetext{
* Correspondence: anuja.darekar@mail.mcgill.ca

${ }^{1}$ School of Physical and Occupational Therapy, Faculty of Medicine, McGill University, Montreal, Quebec, Canada

${ }^{2}$ Feil and Oberfeld Research Center, Jewish Rehabilitation Hospital, Research site of the Montreal Centre for Interdisciplinary Research in Rehabilitation (CRIR), Laval, Quebec, Canada

Full list of author information is available at the end of the article
}

of the promising intervention tools that is sought to facilitate this goal is virtual reality (VR) technology.

VR consists of a range of technologies that can be used to artificially generate sensory information in the form of a virtual environment (VE) that is interactive and perceived as similar to the real world $[9,10]$. Since VEs are interactive and game-like, they encourage active exploration, enhance engagement and provide motivation and enjoyment, thus allowing longer exercise sessions and improved treatment adherence [11-13]. VEs can be designed to resemble real-life scenarios including those encountered in the community $[9,14]$. It is not feasible to physically replicate realistic, community scenarios in the clinic or to safely train patients in the community. VR thus affords therapists with the unique opportunity to expose and train patients in these scenarios in a riskfree, graded manner, while providing intensive training and multi-sensory feedback $[15,16]$. These and other 
factors make VR-based intervention a useful adjunct or alternative to conventional therapy in re-training balance and gait dysfunctions post stroke. A review of the literature to explore the effect of VR-based interventions in retraining balance and gait and promoting independent community ambulation in this population is therefore important.

Several systematic reviews $[17,18]$, meta-analyses $[19,20]$ and a Cochrane review [21] have been undertaken to review the utility of VR technologies in retraining poststroke individuals. Most of these reviews (with one exception [20]) had broader scopes of investigation and included upper limb retraining and/or cognitive rehabilitation. Further, these reviews considered only stronger study designs such as randomized controlled trials (RCT) for inclusion and thereby overlooked studies with different designs. We were, however, interested in examining the evidence on VR interventions on a targeted area (balance and gait post-stroke), with a broader and more flexible inclusion criteria as allowed in scoping reviews [22]. This allowed us to explore the added evidence to identify aspects of VR-based intervention that may prove useful in the treatment of balance and gait dysfunctions post-stroke. Further, we were interested in exploring with this scoping review, the utility of VR-based interventions in enhancing abilities required for community ambulation.

Community ambulation entails independent mobility outside the home [6] and involves dealing with environmental challenges such as low light, uneven terrain, external physical load, traffic, obstacles, time constraints etc. [23]. Various studies define diverse criteria for successful community ambulation [24]. For this review, we used one of the following criteria to identify results predictive of independent community ambulation:

1) post training gait speed $\geq 0.8 \mathrm{~m} / \mathrm{s}, 2)$ functional ambulation category (FAC) of 5 (independent community ambulator) [25], 3) gait outcomes recorded in the community and, 4) outcomes related to negotiation of the environmental challenges (such as slope walking, obstacle negotiation etc.) [23].

The objectives of this scoping review were, therefore, to appraise the current state of information about the effects of VR intervention on balance and gait in poststroke individuals and to explore the utility of VR-based interventions in facilitating independent community ambulation. The scoping review was conducted using the framework of Arksey and O'Malley [22], described in greater detail by Levac et al. [26].

\section{Review}

Search strategy

OVID MEDLINE, OVID EMBASE, PUBMED and PSYCINFO databases were searched using the terms "rehabilitation", "virtual reality", "stroke", "balance", "gait" etc. between the periods January 1950 to December 2013. The search strategies used in Ovid Medline and Pubmed databases are illustrated in Table 1. Similar strategies were employed for the other databases. Furthermore, cross references obtained from the included articles were also considered.

\section{Selection of articles for review}

1696 retrieved articles were first screened for relevance based on their titles and abstracts. Studies that were not published in the English language, available as abstracts only, that did not include post-stroke individuals or included a mixed etiology sample without separate description of outcomes related to the stroke sample, were excluded. Studies that - 1) used VR as a training tool for balance and mobility, 2) reported at least one outcome related to gait or balance and 3) published in the English language were included.

The included articles were scrutinised to extract information about VR systems, the training paradigms, outcomes and results. Twenty-four studies that met the inclusion criteria were retained for this scoping review. The subsequent sub-sections provide a synopsis of the study design, virtual environments (VE), outcome measures and the findings.

\section{Study designs}

Of the included studies, eleven were small RCTs (Level II evidence according to CEBM levels of evidence [27]) [28-38], four were controlled trials with concurrent control group (Level III evidence) [39-42], two studies had no [43] or a historical control group (Level IV evidence)

Table 1 Search strategies

\begin{tabular}{|c|c|c|}
\hline Database & Search strategy & $\begin{array}{l}\text { Articles } \\
\text { retrieved }\end{array}$ \\
\hline Ovid Medline & $\begin{array}{l}\text { Rehabilitation. mp. or Rehabilitation AND } \\
\text { Virtual reality.mp. }\end{array}$ & 485 \\
\hline Ovid Medline & $\begin{array}{l}\text { Virtual reality.mp. AND Stroke/OR postural } \\
\text { balance/OR balance training .mp. OR } \\
\text { Hemiplegia }\end{array}$ & 166 \\
\hline Ovid Medline & $\begin{array}{l}\text { Stroke.mp. or cerebrovascular accident/AND } \\
\text { balance training.mp. or posture/ AND virtual } \\
\text { reality.mp. or user-computer interface }\end{array}$ & 13 \\
\hline Ovid Medline & $\begin{array}{l}\text { Gait.mp. or Gait/or Gait disorders, } \\
\text { Neurologic/Stroke.mp. or "National Institute } \\
\text { of Neurological Disorders and Stroke"/or } \\
\text { Stroke/User-computer interface/or virtual } \\
\text { reality.mp. }\end{array}$ & 50 \\
\hline Pubmed & $\begin{array}{l}\text { "Stroke" [Mesh] OR "National Institute of } \\
\text { Neurological Disorders and Stroke" [Mesh] } \\
\text { AND ("gait"[Mesh] OR "gait disorders, } \\
\text { neurologic" [Mesh]) AND (virtual reality) }\end{array}$ & 133 \\
\hline Pubmed & $\begin{array}{l}\text { "Rehabilitation [Mesh] OR "rehabilitation" } \\
\text { [Subheading] AND (virtual reality) }\end{array}$ & 565 \\
\hline
\end{tabular}


[44] and six studies presented non-empirical evidence consisting of case reports, case series or proof-of-principle studies (Level V evidence) [10,45-50]. The proportion of RCTs has shown a consistent rise over the years, suggesting an increase in methodological rigor of studies in the field.

\section{Participant characteristics}

Some variability with respect to subject characteristics was observed among the included studies. Fifteen studies [28-35,38-40,42,45,47,49,50] recruited subjects with chronic stroke, seven $[10,36,41,43,44,48]$ with sub-acute to chronic stroke, one [37] with acute stroke and one study did not provide information stroke chronicity [46]. Most studies included individuals between the ages of 50 and 80 years. Further, four studies [34-37] recruited in-patients receiving rehabilitation, twelve $[10,28,30,38-40,42,45-48,50]$ recruited community-dwelling participants while seven studies $[29,31,32,41,43,44,49]$ did not provide these details. A typical sample in most studies was thus middle-aged and old, community-dwelling chronic stroke survivors.

\section{VR systems}

Both custom-made and commercially available VR systems were used in studies (Table 2). Custom-made systems were usually laboratory specific and often combined other devices with the VR interface such as robotic devices $[31,33,45]$ treadmills $[10,30,34,40,43]$ and others. Among commercially available systems, two studies used the Interactive Rehabilitation and Exercise system, developed to comply with specific rehabilitation requirements and customization according to the patient's needs [29,32]. Seven studies used over the counter gaming consoles such as the Nintendo Wiir ${ }^{\mathrm{mx}}$, Sony Playstation ${ }^{\mathrm{mm}}$ or the Kinect ${ }^{\mathrm{mm}}$ systems [35,37-39,41,42,47]. These are designed for the general population but are being increasingly used for rehabilitation.

\section{VR-based interventions}

a) VR tasks: The tasks used in the studies generally reflected the training objectives. For instance, studies aimed at improving balance utilized balance training tasks [32,35,37,38,41,46,47] while those aimed at improving gait utilized treadmill walking $[10,28,30,36,40,43,49,50]$ or components of gait training such as ankle range of motion (ROM), strength $[31,33,45]$ or appropriate activation/deactivation of ankle muscles [48].

b) Training dosage: Most studies used training sessions lasting 40-60 min (Table 2). Some studies employed shorter (20 min) training sessions [30,34]. The training frequency varied from 2-5 times per week and total training duration lasted between 2-8 weeks. Consequently, the total VR intervention showed a wide variation ranging between 2 to 22 hours. Typical training doses comprised of sessions of 40-60 min duration, 3-5 times per week for 3-6 weeks.

c) Feedback: Apart from the obvious intrinsic visual feedback perceived from the VE, additional intrinsic auditory, somatosensory or proprioceptive information were manipulated in some studies. For instance, Fung et al. [10] used a six-degree of freedom motion platform to simulate slopes in the VE to impart proprioceptive information congruent to walking on inclined surfaces, while Deutsch et al. [45] used haptic inputs to simulate turbulence or sensation of collision. This multisensory feedback could have acted as an important facilitator of intrinsic learning of the tasks, while enhancing engagement with the VE. Some studies also provided additional extrinsic feedback through knowledge of performance (KP) or knowledge of results (KR). Nine studies provided both KR and KP $[10,29,31,32,38,43-46]$, three studies provided only KR $[28,41,47]$, while others [30,34-37,40,42,48] did not provide or report on provision of KR/KP feedback. KP was provided either by the system $[10,29,32,43,45,46]$ through graphs depicting an outcome or movement quality, or from verbal feedback (about movement quality, area of improvement etc.) by the therapists present during training $[31,38,44]$. KR was usually provided by the system as visual (e.g. success scores, placards) or auditory (e.g. cheering and other sounds) feedback.

Other motor learning principles such as motivation, variable practice, and attention through enhanced engagement were not addressed explicitly in most studies. [Table 2].

\section{Outcome measures}

The outcome measures utilized in the studies reflected body function and activities domain of the International Classification of Function (ICF [51]) and comprised of both laboratory measures and clinical tests. Balance assessment included center of pressure (CoP) measurements (CoP sway, sway velocity etc.) during static (quiet standing) $[32,34,35,46]$, and dynamic postural tasks $[34,36]$ as well as clinical tests such as the Berg Balance Score (BBS) [32,35-38,43,44,47]. Gait related outcomes were commonly measured during overground walking (reflecting transfer of VR training to overground gait) and included gait speed [28,30-32,34,36,38,39,42-44,48-50], spatiotemporal gait parameters (stride length, step length, cadence etc.) $[28,31,32,34,36,49,50]$ and kinematic as well as kinetic gait parameters $[33,48]$. Clinical tests such as Timed-Up and Go (TUG) test $[35,36,38,42,44,46,47]$, the 6 -minute walk test $[28,31,38,39,42,47]$ and Functional Ambulation Category (FAC) $[29,31]$ were also reported. 
Table 2 VR systems and training protocols

\begin{tabular}{|c|c|}
\hline Study & VR system \\
\hline Deutsch et al. (2004) [45] & $\begin{array}{l}\text { Rutgers Ankle - an airplane simulation task required } \\
\text { that the subject control the position of the airplane by } \\
\text { using his ankle through a series of targets and not } \\
\text { contacting them. For experiment 2, haptic effects were } \\
\text { introduced to the Stewart platform and a new } \\
\text { simulation that required the subjects to navigate a boat } \\
\text { was added. }\end{array}$ \\
\hline
\end{tabular}

Jaffe et al. (2004) [28]

You et al. (2005) [29]

Betker et al. (2006) [46]

Fung et al. (2006) [10]

Flynn et. al. (2007) [47]

Yang et. al. (2008) [30]

Dunning et. al. (2008) [48]

Mirelman et al. (2009 [31]; 2010) [33]

Kim et al. (2009) [32]

Walker et al. (2010) [43]
Subjects walked on a motorized treadmill at selfselected walking speeds and viewed the real time display of their legs via a helmet mounted display wherein stationary images of obstacles were introduced. The subjects were required to step over the obstacle (take sufficiently higher and larger steps) to complete the task.

IREX, GestureTek- stepping up and down, Sharkbait and Snowboarding

COP-controlled video-game based exercise games Under Pressure, Memory Match and Tic-Tac-Toe. The system consisted of a pressure mat which mapped the COP movements as the subjects moved. This was synchronized to the game motion software so as to match the COP movements for game play. The users were supposed to move in the AP and the ML direction at different speeds in order to play the games.

VR-based locomotor system with a self-paced treadmill mounted on a 6-degree of freedom of motion platform. Subjects reacted in three VE's with 3 levels of complexity. Each VE involved walking $39 \mathrm{~m}$ within a predetermined time constraint. Progression from one level to the next was permitted only after successful completion of 3 trials within the time constraint, as the level of complexity increased with environmental perturbations and presence of moving obstacles.

EyeToy Play Station 2 gaming system. Games played required dynamic balance, upper extremity ROM, speed, cognition, reaction time and accuracy.

Motorized treadmill placed in front of three $239 \mathrm{~cm}$ wide screens Task consisted of walking in a community VE resembling community scenarios in Taipei and involved negotiating slopes, avoiding obstacles etc. contract and relax the agonist and antagonist muscles of the ankle to complete a "paint" game.

Rutgers Ankle Rehabilitation System - 6-degree of freedom Stewart platform force-feedback system that uses ankle movements to navigate through a VE displayed on a desktop computer as in Deutsch et al. (2004)

IREX VR system - Shark Bait, stepping up/down and snowboard games were used.

BWSTT + VR system - Body-weight supported treadmill training combined with VR. Subjects walked on a Biodex Gait Trainer 2 treadmill with an overhead Biodex Unweighting system while a virtual street scene was projected on to a 51-inch television monitor connected to a desktop. The scene was synchronized to the subjects' motion via an inertial orientation tracking device mounted on a cap worn by the subjects.
SEMG coupled VR system that required the subject to

\section{Training protocol}

Exp 1 - 4 one hour sessions Exp 2 - one hour, 3 times per week for 4 weeks

Control group: stepping over real foam obstacles Experimental group: stepping over virtual obstacles 1 hour sessions, 6 sessions over 2 weeks

Control group: no intervention Experimental group: VR games - 60 minutes per day, 5 times per week for 4 weeks

Eight 45-min exercise sessions over 3 weeks, 3 sessions in $1^{\text {st }}$ and $2^{\text {nd }}$ week each and 2 in the $3^{\text {rd }}$ week.

Both control and stroke subjects received the same intervention. Training frequency or length of single session not defined.

Playing games on the gaming console in the standing position 20 one hour sessions over 4 1/2 weeks.

Control group: treadmill walking while performing various tasks, Experimental group: walking in the VE 20 min per session, 3 sessions per week for 3 weeks.

One hour session, 3 times per week for 8 weeks 30 min functional lower extremity strength training and 30 min sEMG VR training.

Experimental group: Ankle exercises in the form of VR games along with the robot. Control group: training only with the robot, same exercises as the experimental group without VR. One hour sessions, 3 times per week for 4 weeks

Control group - 40 min of conventional physical therapy (CPT) Experimental group - 40 min of CPT + 30 min of VR therapy, 4times/week for 4 weeks

2-3 sessions per week for 4-6 weeks for a total of 12 sessions per subject. Each training session lasted for 10 min initially and the duration was increased for the later sessions as tolerated. 
Table 2 VR systems and training protocols (Continued)

\begin{tabular}{|c|c|c|}
\hline Shin et al. (2010) [39] & $\begin{array}{l}\text { Sony Playstation } 2 \text { Eyetoy play gaming system. Games } \\
\text { such as Goal Attack, Table Tennis, Homerun, Knockout } \\
\text { and Bowling were used. All of the games had a component } \\
\text { of dynamic balance, speed and reaction time training. }\end{array}$ & $\begin{array}{l}\text { Control group: no intervention. Game exercise group: } \\
60 \text {-min sessions, } 3 \text { times per week for } 6 \text { weeks. }\end{array}$ \\
\hline Yang et al. (2011) [34] & $\begin{array}{l}\text { VR Treadmill system consisting of } 4 \text { components: 1) a } \\
\text { commercial treadmill modified to operate at speeds } \\
\text { ranging from } 0.1 \text { to } 1 \mathrm{mph}, 2 \text { ) a personal desktop } \\
\text { computer with a liquid crystal display projector, 3) a VR } \\
\text { training program resembling a video-game developed }\end{array}$ & $\begin{array}{l}\text { Both groups: treadmill training (duration } 20 \text { min), three } \\
\text { times per week for } 3 \text { weeks + regular therapy sessions. } \\
\text { Experimental group: walking on the treadmill in the VE } \\
\text { while stepping on the switches to affect turns. Control } \\
\text { group: level walking on the treadmill without VR }\end{array}$ \\
\hline
\end{tabular}
from commercial software (3DWeb, superspace) consisting of scenes that involved walking in a park along a pathway with eight left and right turns respectively, and indoor activities such as turning a light on/off and opening doors, 4) interactive switches located on each side of the treadmill - stepping switches to turn left/right and touch switch for hand motion tasks.

Cikaljo et al. (2012) [44]

Cho et al. (2012) [35]

Feasel et al. (2011) [49] and Lewek et al. (2012) [50]

Jung et al. (2012) [40]

Kim et al. (2012) [41]

Cho et al. (2013) [36]
Balance Trainer (BT; Medica Medizin-technik GmbH) standing frame fixed to the base with passive controllable springs that control the stiffness of the standing frame which can move within two-degrees of freedom (AP, ML and combinations of both). Virtual environment was built in the $3 \mathrm{D}$ rendering program and involved moving along a path (through AP and ML movements) towards a goal while avoiding collisions with obstacles in the path.

Conventional 42-inch LCD TV connected to a balance board gaming system (Wii Fit Balance Board, Nintendo, Japan). Commercially available games on the Wii such as balance bubble, ski slalom, ski jump, soccer heading, table tiling and penguin slide were used for training.

Integrated Virtual Environment Rehabilitation Treadmill (IVERT) system consisting of an instrumented dual-belt treadmill coupled to an immersive VE. The treadmill utilized a control algorithm to drive the treadmill speed in congruence with the user's gait speed (estimated from the ground reaction force). VE consisted of a park with rolling hills, trees, rocks and a trail lined with fence posts. The VE was displayed with the help of three short-throw projectors that were mounted in front of a three-panel display placed a distance of $1.2 \mathrm{~m}$ from the front and $0.9 \mathrm{~m}$ at the sides respectively. The combined image display had a $170^{\circ}$ horizontal and $60^{\circ}$ vertical field-ofview. Asymmetry in gait was portrayed as a curved path in the VE and users were encouraged to maintain a straight path during trials.

The set-up consisted of a treadmill and an HMD through the virtual scene was displayed. The virtual scene consisted of a park stroll. The HMD displayed a 100-inch screen and had built-in earphones. Further information about the virtual scene and synchronization of the treadmill with the VR was not provided.

Nintendo Wii sports software to play games involving tennis and boxing. The Wii games were displayed on a 30-inch TV display placed at $60 \mathrm{~cm}$ above the ground atop which was mounted the motion sensor. The motion sensor communicated with a remote that was either held on or strapped to the unaffected hand of the stroke subjects. Both games required varied motion and acceleration patterns to succeed.

The set-up utilized a treadmill, a laptop, projector and speakers. The laptop was used to project real-world video recordings (VRRW) on to the projector which consisted of 10-min recordings of a $400 \mathrm{~m}$ walk track, a rainy $400 \mathrm{~m}$ walking track, a $400 \mathrm{~m}$ walking track with obstacles, walk in the community during daytime and nighttime and walking on a trail. Each recording was repeated thrice during the 30 min training period.
Experimental group: $\mathrm{BT}+\mathrm{VR}-20$ min per session, 5 times per week for 3 weeks (2 weeks clinic +1 week telerehabilitation) Control group: BT - 20 min per session, 5 times per week for 4 weeks.

Both groups: standard rehabilitation program. Experimental group: additional 30-minVR training thrice a week for 6 weeks.

Feasel et al:: One session consisting of 20-40 min of treadmill walking. Lewek et al.: Two post-stroke individuals performed 18 sessions over 6 weeks consisting of 20 min walking with the IVERT system followed by $10-$ $15 \mathrm{~min}$ of overground walking. Each session lasted for 60 min (patient 1) or 45 min (patient 2).

Experimental group: Treadmill walking with VR $30 \mathrm{~min} /$ day, walking without $\mathrm{VR}$, following the same schedule as for experimental group.

Both groups received general exercises (not specified) for $30 \mathrm{~min}$ and electrical stimulation to the tibialis anterior muscle on the paretic side for $15 \mathrm{~min}$. The experimental group received additional VR training for $30 \mathrm{~min} / \mathrm{session}$, three times a week for 3 weeks.

Both groups: standard rehabilitation program, $80 \mathrm{~min}$ per day, 5 times a week for 6 weeks. Experimental group: VRRW training, 30 min a day, 3 times per week for 6 weeks. Control group: treadmill training without VR for similar duration. 5 days/week for 5 weeks. Control group: treadmill 
Table 2 VR systems and training protocols (Continued)

\begin{tabular}{|c|c|c|}
\hline Fritz et al. (2013) [38] & $\begin{array}{l}\text { Nintendo Wii (Wii sports and Wii Fit) as well as } \\
\text { Playstation (Eyetoy play and Kinect) gaming systems } \\
\text { were used to train the experimental group. The Wii Fit } \\
\text { and Kinect were marketed as physical activity whereas Wii } \\
\text { sports and Eyetoy were marketed as 'fun-based' games. } \\
\text { The patients were encouraged to operate both systems on } \\
\text { their own. }\end{array}$ & $\begin{array}{l}\text { Control group: no intervention VR group: } 50-1 \text { hour } \\
\text { sessions consisting of } 25-30 \text { min physical activity and } \\
25-30 \text { min fun-based games. Frequency: } 4 \text { days/week for } \\
5 \text { weeks. }\end{array}$ \\
\hline Rajaratnam et al. (2013) [37] & $\begin{array}{l}\text { Nintendo Wii-fit and the Kinect gaming system were } \\
\text { used to train the experimental group. Games that } \\
\text { required subjects to shift weight in standing (Wii Fit and } \\
\text { Kinect) and sitting (Kinect only) were used for training. }\end{array}$ & $\begin{array}{l}\text { Control group: } 60 \text { minutes of conventional rehabilitation } \\
\text { per session for } 15 \text { sessions. Experimental group: } 40 \text { min of } \\
\text { conventional rehabilitation + } 20 \text { min of VR training per } \\
\text { session for } 15 \text { sessions. }\end{array}$ \\
\hline Singh et al., (2013) [42] & $\begin{array}{l}\text { Nintendo Wii Fit plus with Balance Board: Balance } \\
\text { Bubble game Xbox } 360 \text { Kinect: Rally Ball game, } \\
\text { individuals who scored a gold medal on this game } \\
\text { progressed on to the Reflex Ridge game. }\end{array}$ & $\begin{array}{l}\text { Control group: standard group exercise therapy } 2 \text { hour } \\
\text { sessions } 2 \text { times per week for } 6 \text { weeks. Experimental } \\
\text { group: } 90 \text { minutes of standard group exercise }+30 \text { min } \\
\text { of VR balance games, } 15 \text { min each on the WiiFit and } \\
\text { Xbox Kinect, twice per week for } 6 \text { weeks. }\end{array}$ \\
\hline
\end{tabular}

Two studies measured ambulation in the community environment. Yang et al. [30] used the community walk test (time taken to walk $400 \mathrm{~m}$ in a community environment) while Mirelman et al. [31] reported on community walking activity (number of steps/day, average daily distance walked, speed, cadence etc.) using the Patient Activity Monitor. In addition, few studies reported outcomes reflecting challenges encountered during community ambulation. For e.g. Jaffe et al. [28] reported the obstacle test (the longest obstacle successfully crossed among a range of obstacle heights and lengths) and Fung et al. [10] reported on meeting time constraints, slope walking and obstacle avoidance. The details of all the outcomes reported can be found in Table 3 .

\section{Effectiveness of VR-based interventions}

Varying results were obtained in CoP measures comparing VR-based interventions with non-VR-based interventions. While no significant differences among VR-based and other interventions were found for CoP measures during static balance tasks, significant differences between interventions were noted in these measures during dynamic balance tasks. For example, Yang et al. [34] found a significant improvement in bilateral symmetry and CoP excursion under the paretic leg during the sit-to-stand task, while Kim et al. [32] reported a significant improvement in sway angles during a dynamic weight shift task only following a VR-based intervention. Similarly, for clinical measures of balance, five studies reported significant improvements in BBS scores [32,35,36,43,47] and two studies $[37,47]$ reported an improvement on the Functional Reach Test following VR intervention as compared to other interventions.

Ten of the fourteen studies that reported gait speed found significant increases after VR-based intervention in comparison with other interventions. In addition, significant improvements in other spatiotemporal gait parameters such as cadence [32], step length [32,36,50], step time [32], stride length [36] and gait symmetry [50] as well as improvements in ankle, knee and hip ROM, and greater ankle moment and power were found following VR-based intervention [33,48] over other interventions. (Please see Table 3 for a detailed account of the results).

Further, we examined study outcomes using our criteria for independent community ambulation. Participants from four studies were able to achieve an average gait speed of $\geq 0.8 \mathrm{~m} / \mathrm{s}$ following VR intervention $[30,31,36,38]$. Also, among participants who received VR-based intervention, 3/5 participants from You et al. [29] and 4/9 participants from Mirelman et al. [31] achieved an FAC of 5 placing them in the unlimited community ambulation category. In addition, when gait measures included community walking, Yang et al. [30] and Mirelman et al. [31] found significant increases in community ambulation time and community ambulation distance and speed respectively following VR intervention. Furthermore, Jaffe et al. [28] and Fung et al. [10] also found improvements in the ability to negotiate perturbations encountered in the community such as slopes and obstacles. An increase in gait speed of $\geq 0.8 \mathrm{~m} / \mathrm{s}$, improvement on FAC, improvement in community ambulation measures, as well as increased competency in dealing with environmental perturbations, could lead to independent community ambulation in some participants. These improvements were not seen following other interventions, suggesting an added advantage of VR-based interventions over other interventions in facilitating independent community ambulation.

One study [29] explored the effect of VR intervention on cortical re-organization post-stroke, wherein a significant shift from bilateral (pre-training) to ipsilesional (posttraining) activation of the primary sensory-motor cortex during walking-like movements was found, suggesting that VR-based training can facilitate neuroplastic changes in the cortex. 
Table 3 Summary of studies

\begin{tabular}{|c|c|c|c|c|}
\hline Study & $\begin{array}{l}\text { Design, level } \\
\text { of evidence }\end{array}$ & $\begin{array}{l}\text { Population N, age, } \\
\text { duration post-stroke }\end{array}$ & Type of stroke & Outcome measures \\
\hline $\begin{array}{l}\text { Deutsch } \\
\text { et al. (2004) } \\
{[45]}\end{array}$ & Pilot study, V & $\begin{array}{l}\text { Chronic stroke } \\
\text { Experiment } 1 \text { - } 69 \text {-year } \\
\text { old, } 10 \text { months post-stroke } \\
(n=1) \text { Experiment } 2-1-8 \\
\text { years post-stroke }(n=3) \text {, age } \\
\text { not given }\end{array}$ & $\begin{array}{l}\text { Exp 1- Right middle cerebral } \\
\text { artery CVA Exp } 2 \text { - not specified }\end{array}$ & $\begin{array}{l}\text { Exp 1) VR-based measures } \\
\text { including power, torque, } \\
\text { accuracy,strength and } \\
\text { range of motion Exp 2) } \\
\text { Walking speed; 6-minute } \\
\text { walk test (6MWT); Berg } \\
\text { Balance score (BBS); foot } \\
\text { strength }\end{array}$ \\
\hline
\end{tabular}

Jaffe et al. Randomized

(2004) [28] controlled

trial, II
Chronic stroke $(3.8 \pm 2.2$ years Not specified post-stroke), $60.7 \pm 2.3$ years; virtual object group $(n=10)$; real object group $(n=10)$
You et al. (2005) [29]

\section{Experimenter}

blind

randomized study - RCT, II
Chronic stroke (VR group $-n=5,54.6 \pm 3.0$ years, $18.2 \pm 2.3$ months post-stroke control group $-\mathrm{n}=5$, $54.6 \pm 3.4$ years, $19.4 \pm$ 4.3 months post-stroke)
Betker et al. Single-subject $n=3$, case 1 - 20-year old (2006) [46] design: case report, $\mathrm{V}$ case 2 - 58-year old post-stroke (onset not provided) case 3-14-year old
Thalamic hemorrhage $(n=2)$ Corona radiata hemorrhage $(n=3)$ Corona radiata infarct $(n=5)$
Percentage improvement on: 1) Balance tests (natural stance, natural stance eyes closed, on toes, tandem stance, tandem stance eyes closed, left leg only, right leg only) 2) Walking tests (walking velocity, cadence and stride length at self-selected and fast walking) 3) Obstacle test 4) 6-minute walk test (6MWT)

1) $\mathrm{fMRI}$ - Laterality Index (LI) 2) Functional Ambulation Category (FAC) 3) Modified Motor Assessment Scale (MMAS)
Case 1- cerebellar tumour excision with ataxia Case 2 - cerebrovascular accident infarction Case 3 - closed TBI (case 1 and 3 will not be discussed in the paper)
1) Tasks that involved maintaining static and dynamic balance 2) CoP excursion and sway path 3) Number of falls
Fung et al. Feasibility (2006) [10] study, V

\author{
Sub-acute stroke $(n=2,49 \& \quad$ Not specified \\ 61 years, 2 and 4.5 months \\ post-stroke) Control - healthy \\ elderly ( $n=1,64$ years)
}

Ability to complete the locomotor task within the time constraint and without any collisions with the virtual obstacles.
Results

Exp 1) One grade increase in the strength of ankle evertors. Increased accuracy on the VR simulations (from $58 \%$ to $88 \%$ ). Exp 2 -Increase in strength increase in 2 to 4 muscle groups and increase in walking speed $(80 \mathrm{ft} / \mathrm{min}$ to $95 \mathrm{ft} / \mathrm{min}$ ).

1) Results related to the Balance tests are not reported. 2) Greater percent improvements in walking speed $(20.5 \%$ vs. $12.2 \%)$ and stride length for fast walking with VR 3) Obstacle crossing showed greater percent improvements with virtual obstacle protocol. Greater than 95\% retention in all key gait parameters at 2 week follow-up 4) 6MWT: No significant changes post-treatment observed in both groups.

1) Bilateral activity in the sensory-motor cortex as seen before treatment either disappeared or decreased on the ipsilateral side indicating cortical reorganization. 2) All patients in the VR group were able to achieve a change of at least one level on the FAC as opposed to the control group. 3) Significant changes in MMAS.

1) Successful completion of oscillating head rotations, trunk bending and trunk rotation tasks post-exercise as opposed to failure preexercise. 2) Variable findings on CoP excursion and CoP sway path with increase in excursion and sway path in some and decrease in other tasks. 3) 5 falls pre-exercise as opposed to 2 falls post-exercise

Both subjects as well as the control were able to increase the walking speed to complete level 1 in all VE's. The subjects were also able to eventually complete level 2 despite a considerable reduction in gait speed while negotiating platform movements. Both subjects did not reach level 3 to avoid obstacles successfully. The precise increase or decrease in gait speed is not specified. 
Table 3 Summary of studies (Continued)

\begin{tabular}{|c|c|c|c|c|c|}
\hline $\begin{array}{l}\text { Flynn et al. } \\
\text { (2007) [47] }\end{array}$ & Case report, V & $\begin{array}{l}\text { Chronic stroke }(n=1 \text {, } \\
17 \text { months post-stroke, } \\
76 \text {-year old) }\end{array}$ & $\begin{array}{l}\text { Cerebro-vascular accident, } \\
\text { area not specified }\end{array}$ & $\begin{array}{l}\text { Only those concerned with } \\
\text { balance and mobility are } \\
\text { listed here: 1) BBS 2) } \\
\text { Dynamic Gait Index (DGl) 3) } \\
\text { Timed Up-and-Go (TUG) 4) } \\
6 \text { MWT 5) Functional Reach } \\
\text { test (FRT) }\end{array}$ & $\begin{array}{l}\text { Only those concerned with } \\
\text { balance and mobility are } \\
\text { listed here: 1) BBS increased } \\
\text { from } 51 / 56 \text { pretest to } 54 / 56 \\
\text { post-test 2) DGl - } 16 \text { pre-test } \\
\text { to } 21 \text { post-test 3) TUG - } 12.73 \mathrm{~s} \\
\text { pre to } 11.68 \mathrm{~s} \text { post } 4) \\
6 \mathrm{MWT}-1282 \mathrm{ft} \text { pre to } \\
1337 \mathrm{ft} \text { post 5) FRT } 11.33 \text { in } \\
\text { pre to } 11.50 \text { in post }\end{array}$ \\
\hline
\end{tabular}

$\begin{array}{ll}\text { Yang et al. } \quad \text { RCT, II } & \text { Chronic stroke: VR group } \\ \text { (2008) [30] } & \\ & \\ & \text { post-stroke) Control group } \\ & (n=9,60.9 \text { years, } 6.1 \text { years } \\ & \text { post-stroke) }\end{array}$

Dunning Case report, $V$ Sub-acute stroke $(n=1$, et al. (2008) [48]
Not specified

Ischaemic infarct in the 51 years; 9 months post-stroke) posterior limb of the left internal capsule
Mirelman Randomized et al. (2009; controlled 2010) $[31 ; 33]$

trial, II
Chronic stroke Robotic VR group $(n=9 ; 61.8$ years, 37.7 months post-stroke), robotic group $(n=9$; 61 years, 58.2 months post-stroke)
1) Walking speed 2) Community walking time 3 ) Activities-specific Balance Confidence scale (ABC) 4) Walking Ability Questionnaire (WAQ) score

1) Modified Emory Functional Ambulation Profile (mEFAP) 2) Lower extremity portion of the Fugl-Meyer (FM) scale 3) Gait velocity: self-selected \& fast 4) Temporal distance gait parameters 5) Lower extremity joint kinematics and kinetics
1) Insignificant change in walking speed but a trend towards increase. 2) Significant improvement in community ambulation time (6.14 \pm 5.53 s); 3) ABC scores (8.86 \pm 10.10 points); 4) WAQ scores ( $3.45 \pm 5.11$ points); All gains retained at 1 month follow-up.

1) $\mathrm{mEFAP}-4.4 \mathrm{~s}(11.2 \%)$ decrease post-intervention 2) FM - 5 point (23.8\%) increase with largest changes for obstacles (17.2\%) and stairs (13.7\%) 3) Gait velocity increase post-intervention -Slow $0.29 \mathrm{~m} / \mathrm{s}(27.7 \%)$ fast $0.26 \mathrm{~m} / \mathrm{s}$ (16.4\%) 4) Temporal distance gait parameters such as step length, cadence, stance and swing times also showed minor improvements post-treatment. 5) Ankle plantarflexor moment during push off increased 29.5\% and $13.3 \%$ for self-selected and fast walking speeds respectively Greater hip extension at push off, improved knee extension at heel strike and greater ankle plantarflexion at push-off.

1) $6 \mathrm{MWT}$ 2) Community-based walking as measured by the PAM (no. of steps/day, average daily distance walked, speed, cadence, walking strides, maximum walking speed, longest consecutive locomotion period in minutes and longes consecutive distance travelled). 3) Self selected walking speed (SSWS) 4) Joint kinetics - ankle moments during stance and pre-swing, knee flexor moment during stance and push-off, hip flexor moment at initial swing, power at the ankle, knee and hip joints 5) Joint kinematics - ROM of the ankle and hip joints during the gait cycle
$6 \mathrm{MWT}-21 \%$ increase in the Robotic VR group; 0.5\% increase in the robotic group 2) Community based ambulation - significant walked, no. of steps per day, average speed and

maximum speed. All changes were retained in the robotic VR group at 3 months follow -up. 3 SSWS $-24 \%$ increase (from 0.65 to $0.81 \mathrm{~m} / \mathrm{s}$ ) in the VR group vs. $2 \%(0.67-0.68 \mathrm{~m} / \mathrm{s})$ in the NVR group. 4) Joint kinetics- Ankle moment (barefoot walking) - VR group (from $0.74 \pm 0.24 \mathrm{Nm} / \mathrm{kg}$ to $0.90 \pm 0.31 \mathrm{Nm} / \mathrm{kg}, 21 \%$ ) vs. NVR group $(0.68 \pm 0.17 \mathrm{Nm} / \mathrm{kg}$ to $0.67 \pm 0.08 \mathrm{Nm} / \mathrm{kg}, 1.5 \%)$. Ankle power (barefoot walking) - significant increase in the VR group $(0.63 \pm$ differences seen in distance 
Table 3 Summary of studies (Continued)

Kim et al. $\quad R C T$, I (2009) [32]
Walker Pre-post et al. (2010) design, IV [43]

\author{
Shin et al. Pre-post, III Chronic stroke (Control \\ (2010) [39] \\ group, $n=16,60.7 \pm$ \\ 9.2 years, 71.5 \\ \pm 33.9 months post-stroke; \\ Game exercise group, \\ $\mathrm{n}=16,60.8 \pm 7.5$ years \\ $69.2 \pm 36.4$ months \\ post-stroke)
}

\footnotetext{
Yang et al. Randomized Chronic stroke (control

(2011) [34] controlled trial, II group, $n=7 ; 65.7 \pm 5.9$ years, $16.3 \pm 10.4$ months post-
}

Chronic stroke: Experimental group ( $n=12 ; 52.4$ years, 25.9 months post-stroke); Control group $(n=12$; 52.4 years, 25.9 months post-stroke)
Intra-cranial hemorrhage in the thalamus, putamen, basal ganglia $(n=13)$ Infarcts in the deep cerebral white matter, basal ganglia, putamen and pons $(n=11)$
Sub-acute to chronic stroke (3 weeks to 1 year poststroke) $N=6,53.4$ years (49-74 years)
1) BBS 2) Modified motor assessment scale 3) $10 \mathrm{~m}$ walk test 4) mean CoP sway area; sway path and maximal sway velocity; antero-posterior (AP) and medio-lateral (ML) sway angles 5) Temporal distance gait parameters: cadence, velocity, step time, stance time, swing time, single/ double support time, step/ stride length.

Ischaemic stroke with left-side hemiparesis

1) FGA 2) BBS 3) Overground walking speed Also reported pre-post treadmill walking speed, treadmill walking duration and percentage body-weight supported

1) $10 \mathrm{~m}$ walk test 2) $6 \mathrm{MWT}$

Control group - 11 ischemic and 5 hemorrhagic stroke; Game exercise group - 10 ischemic and 6 hemorrhagic stroke
$0.28 \mathrm{~W} / \mathrm{kg}$ to $0.91 \pm 0.45 \mathrm{~W} / \mathrm{kg}$; 44\%) as

opposed to the NVR group $(0.5 \pm 0.27 \mathrm{~W} / \mathrm{kg}$ to $0.52 \pm$ $0.26 \mathrm{~W} / \mathrm{kg} ; 4 \%)$. Retention at follow-up was seen in the VR group. 5) Kinematics -Barefoot walking Ankle ROM - increase from $29.3 \pm 7.4$ degrees (19.5\%) in the VR group and from $32.6 \pm 13.4$ to $36.7 \pm 3.2$ degrees (3.3\%) in the NVR. Both changes were reported to be statistically significant. Knee ROM - significantly greater increases (stance-34\%, swing - 15.7\%) in the VR group as compared to the NVR group (stance $-7.2 \%$, swing $-3.9 \%$ ). Both ankle and knee ROM gains were preserved at follow-up. Onset of push-off - improved from $55 \%$ of gait cycle in both groups to $57.7 \%$ of the gait cycle in the VR group only.

\section{$1,2,3)$ Significant} improvement in scores 4) reduction in sway area and maximal CoP velocity; AP and ML sway angles increased 5) cadence, step time, step length showed significant increases

Significant increases in 1) FGA (30\%); 2) BBS (10\%); and 3) overground walking speed $(38 \%$, change of $0.19 \mathrm{~m} / \mathrm{s}$ pre-post). Treadmill walking duration - pre -10 min, post- 19.83 min Treadmill walking speed pre $-1.31 \mathrm{mph}$, post -1.7 mph Weight support (\% Body weight) - pre- 31.67 , post -18.33 .

1) Significant improvements in gait speed $(0.86 \pm 0.32 \mathrm{~m} / \mathrm{s}$ pre-training to $1.10 \pm 0.34 \mathrm{~m} /$ $s$ post-training) in the gameexercise group as compared to controls. 2) Significant improvements were also seen in distance walked in the 6MWT $(225.87 \pm 60.16 \mathrm{~m}$ pre-training to $268.79 \pm$ $56.42 \mathrm{~m}$ post-training) and was significantly larger than that seen in control group.

\section{Not specified}

1) Standing eyes open -Maximum CoP displacement in the ML
1) Standing eyes open: No statistically significant change in any parameters. A 
Table 3 Summary of studies (Continued)

stroke Experimental group, $\mathrm{n}$

$=7,56.3 \pm 10.2,17.0 \pm$

8.6 months post-stroke).

$\begin{array}{lll}\text { Cikaljo } & \text { Pre-post } & \text { Sub-acute stroke (control } \\ \text { et al. (2012) } & \text { (follow-up } & \text { group: } n=22, \text { age: } 61.0 \pm \\ \text { [44] } & \text { only for the } & 7.4 \text { years) Experimental } \\ & \text { experimental } & \text { group: } n=6,58.5 \pm \\ & \text { group), IV } & 12.1 \text { years) }\end{array}$

Cho et al. RCT, II

(2012) [35]
Chronic stroke (experimental Not described

group: $n=11$, age: $65.3 \pm$ 8.4 years, $12.54 \pm$

2.58 months post-stroke; control group: $n=11$, age: $63.3 \pm 6.9$ years, $12.6 \pm$

2.5 months post-stroke)
Not mentioned

(n)
(COPML) \& AP (COPAP)

directions, excursion (COPE), sway area (CoPA), \& bilatera limb-loading symmetrical index (SI). 2) Sit to stand (STS): those included above + CoP excursion for the paretic foot (CoPE/P). 3) Walking: Stance time of the paretic limb (ST/P), number of steps of the paretic limb \& contact area of the paretic foot.

1) BBS 2) TUG 3) 10 meter walk time 4) Single leg stance on affected (SAE) and unaffected (SAU) side. 5) Additional outcomes for the experimental group: VR performance time and number of collisions.

Static balance using postural sway velocity (PSV) in the $\mathrm{AP}$ and $\mathrm{ML}$ directions with eyes open (EO) and eyes closed (EC) 1) PSV - APEO, 2) PSV - MLEO, 3) PSV - APEC, 4) PSV-MLEC. Dynamic balance 5) BBS score, 6) TUG (s)

tendency towards increase in COPML, COPAP, COPE, SI and CoPA in the experimental group. 2) STS: a significant improvement in $\mathrm{SI}$ and CoPE/P in the experimental group. 3) Walking: Significant increase in stance time of the paretic limb in both groups. Significant increase in the contact area of the paretic foot in the experimental group.

$1,2,3,4)$ No statistically significant between group differences on any clinical outcome. Both groups improved over time on the clinical tests. 5) The experimental group showed improved performance and decrease in the number of collisions post- intervention.

Static balance PSV measures (1,2,3 and 4) did not show statistically significant changes pre and post treatment in both experimental and control group. 5) BBS: BBS scores improved in both groups post treatment; greater increase in the experimental (VR) group. 6) TUG: A significant decrease in TUG times in both groups, decrease significantly larger in the experimental VR group.

Feasel et al. 1) Gait velocity

Feasel et al. - Not described Feasel et al. 1) Gait velocity Lewek et al.- Patient 1 - right $\quad$ 2) Overground gait symmetry internal carotid artery stroke Patient 2 - embolic stroke to the left middle cerebral artery

before and after training for stance time, single support time and step length at comfortable and fast walking speeds. 3) Patients' comments about usability (ease of learning, what was easy or hard, what they liked and did not like about the experience) Lewek et al.: 1) Gait speed (comfortable (CGS) and fast walking (FGS)), 2) Step length asymmetry ratio, 3) Stance time asymmetry ratio in the first 5 min of treadmil walking was comparable to overground walking 2) No significant difference in gait symmetry between the first and the last minute of walking. The 'best minute' of symmetry was significantly more symmetric than the first minute. No significant differences in average gait symmetry before and immediately after training. 3) Participants reported the task to be mentally taxing. However, positive comments about having visual feedback (walking in the VE) and having a visual goal (keeping the walking path straight) were received. Lewek et al.: 1) Patient 1 improved the CGS from $0.49 \mathrm{~m} / \mathrm{s}$ (using a large-base quad cane) to $0.84 \mathrm{~m} / \mathrm{s}$ post-training (without using a cane). This improvement 
Table 3 Summary of studies (Continued)

Jung et al. Pre-post (2012) [40] design, III

Kim et al. Pre-post (2012) [41] design, III

Cho et al. RCT, II

(2013) [36]
Chronic stroke (control group: $\mathrm{n}=10$, age $63.6 \pm$ 5.1 years, $15.4 \pm 4.7$ months post-stroke; experimental group: $\mathrm{n}=11$, age $60.5 \pm$ 8.6 years, $12.6 \pm 3.3$ months post-stroke
Control group: 5 ischemic, 5 1) TUG (s) 2) ABC (\%) hemorrhagic and 6 right, 4

left paretic stroke;

Experimental group: 7 ischemic, 4 hemorrhagic and 5 right, 6 left paretic stroke was preserved over the follow-up. The FGS also improved from $0.56 \mathrm{~m} / \mathrm{s}$ pre-training to $0.95 \mathrm{~m} / \mathrm{s}$ post-training. Similar results were seen with patient 2, CGS improved from $1.02 \mathrm{~m} / \mathrm{s}$ pre-training to $1.28 \mathrm{~m} / \mathrm{s}$ post-training (retained on follow-up) while FGS improved from 1.71 to $1.88 \mathrm{~m} / \mathrm{s}$ (retained on follow-up). 2) Step-length symmetry improved from 1.52 to 1.32 (with cane) and 1.18 (without cane) in patient 1 . The positive effects were maintained on follow-up. Patient 2 did not demonstrate step-length asymmetry to begin with. 3) Stance-time asymmetry did not improve in Patient 1, but improved from 1.11 pre-training to 1.04 posttraining. These effects were lost to some degree on follow-up.

Both groups improved significantly on outcomes 1 and 2 (TUG change: control: $-0.8 \pm 0.7 \mathrm{~s}$, stroke: $-2.7 \pm 1.9$ s; ABC change: control: $4.3 \pm 3.3 \%$; stroke: $9.5 \pm 6.0 \%$ ). Improvements seen in the experimental group were significantly larger than the control group.
Control group - 3 hemorrhagic, 4 ischemic stroke, Experimental group - 4 hemorrhagic, 6 ischemic stroke

6.1 months post-stroke; experimental: $n=10$, age $41.3 \pm 6.6$ years, $12.6 \pm$ 7.1 months post-stroke

Sub-acute to chronic stroke (control group: $\mathrm{n}=7$, age $65.1 \pm 4.7 \mathrm{yrs}$; experimental group: $n=7$, age $64.6 \pm 4.4 \mathrm{yrs})$
Control group: 5 ischemic, 2 Walking balance: 1) BBS, 2) hemorrhagic; Experimental TUG (s), Temporal gait group: 4 ischemic, 3 hemorrhagic parameters: 3) Gait speed $(\mathrm{cm} / \mathrm{s}), 4)$ Cadence (steps/
1) Postural assessment scale for stroke patients (PASS), 2) MMAS, 3) Functional Independence measure (FIM)
\& 2) Both groups showed significant improvements on the PASS and MMAS. The experimental group improved significantly more than the control group. 3) No significant differences were found on the FIM scores both within and between groups.

Both groups showed significant improvements on all outcome measure post-test as compared to pre-test (1-7). min), Spatial gait parameters (paretic side): 5) Step length $(\mathrm{cm}), 6)$ Stride length $(\mathrm{cm})$, 7) Single limb support (\%)

The change seen post-test was significantly greater in experimental group as compared to the control group in BBS scores, TUG, gait speed and cadence (1-4).
No between or within group difference on any outcome (1-8). The effect sizes for the outcomes in the VR group were larger than those seen in the control group. These changes were preserved at the 3-month follow-up.
Control group: 4 left, 9 right $\quad$ 1) FM
paretic stroke; Experimental $\quad$ 2) BBS
group: 9 left, 6 right paretic 3) DGl
4) $6 \mathrm{MWT}$
5) $3 \mathrm{~m}$ walk test
6) 3 m walk test - fast
7) Stroke Impact scale
8) TUG

\footnotetext{
Fritz et al. Randomized Chronic community

(2013) [38] matched single blind design, III dwelling stroke (control 10.1 $n=13$, age $64.5 \pm$ post-stroke; Experimental group: $n=15$, age $67.6 \pm$ 9.3 years, $2.5 \pm 2.6$ yrs post stroke)
} 
Table 3 Summary of studies (Continued)

\begin{tabular}{|c|c|c|c|c|c|}
\hline $\begin{array}{l}\text { Rajaratnam } \\
\text { et al. (2013) } \\
{[37]}\end{array}$ & $\begin{array}{l}\text { Randomized } \\
\text { controlled } \\
\text { trial, II }\end{array}$ & $\begin{array}{l}\text { Acute stroke (control group: } \\
\mathrm{n}=9,65.3 \pm 9.6 \mathrm{yrs} ; \\
\text { Experimental group: } \mathrm{n}=10 \\
58.7 \pm 8.6 \mathrm{yrs} \text { ) }\end{array}$ & $\begin{array}{l}\text { Control group: } 8 \text { ischemic, } 1 \\
\text { hemorrhagic; Experimental } \\
\text { group: } 8 \text { ischemic, } 2 \\
\text { hemorrhagic }\end{array}$ & $\begin{array}{l}\text { 1) FRT } \\
\text { 2) TUG } \\
\text { 3) BBS } \\
\text { 4) COP sway } \\
\text { 5) Modified Barthel Index } \\
\text { (MBI) }\end{array}$ & $\begin{array}{l}\text { Both the control and } \\
\text { experimental group showed } \\
\text { significant improvements in } \\
\text { the TUG (2) and the MBI (5) } \\
\text { post-intervention. There were } \\
\text { significant improvements in } \\
\text { FRT (1) post-intervention in } \\
\text { only the experimental group. }\end{array}$ \\
\hline $\begin{array}{l}\text { Singh et al. } \\
\text { (2013) [42] }\end{array}$ & $\begin{array}{l}\text { Controlled } \\
\text { pre-post de- } \\
\text { sign, III }\end{array}$ & $\begin{array}{l}\text { Chronic community- } \\
\text { dwelling stroke (Control } \\
\text { group: } n=13 \text {, age: } 67 \pm \\
8.4 \text { yrs; experimental group: } \\
n=15 \text {, age: } 65.4 \pm 9.8 \text { yrs). }\end{array}$ & Not specified & $\begin{array}{l}\text { 1) TUG } \\
\text { 2) } 30 \text { s sit to stand test } \\
\text { (30sSTS) } \\
\text { 3) Timed } 10 \text { m walk } \\
\text { 4) } 6 \mathrm{MWT} \\
\text { 5) Overall balance score } \\
\text { (OBS): RMS of the combined } \\
\text { AP and ML sway } \\
\text { 6) Barthel Index }\end{array}$ & $\begin{array}{l}\text { Both the control and } \\
\text { experimental group showed } \\
\text { significant gains in TUG (1) } \\
\text { and 30s STS (2) tests } \\
\text { post-training. However, no } \\
\text { difference between control } \\
\text { and experimental groups } \\
\text { were found post-training on } \\
\text { any outcome. }\end{array}$ \\
\hline
\end{tabular}

\section{Discussion}

This scoping review was undertaken to appraise the impact of VR intervention on balance and gait in people post-stroke. Since our review included studies published up to December 2013, we were able to include additional papers as compared to the recent reviews $[18,19]$. Findings from this review indicate that VR-based interventions have an added advantage over conventional interventions in the improvement of balance while performing functional tasks, as well as in the improvement of gait speed and the quality of gait. Preliminary results also suggest that VR-based interventions may prove advantageous in promoting independent community ambulation. Some of the factors (e.g., repetitive variable practice, enhanced engagement, motivation, added feedback etc.) associated with the VR systems and the training paradigms used could be responsible for this added benefit.

\section{VR systems}

An accurate estimation of the VR system that yielded maximum gains could not be obtained from this review. Both customized and commercially available systems seemed to have equally beneficial effects over non-VRbased interventions. A recent review by Lohse et al. [19] also reported a similar view.

\section{VR-based interventions}

Intensive, task specific, variable practice in enriched environments with extrinsic (additional) feedback facilitates motor learning [52]. All of the studies included in this review used some or all of these components during VR training. However, some variability in the utilization of learning principles was found.

a) VR tasks: The congruence of the study objectives, VR tasks and outcomes was an important factor that influenced results. For instance, outcomes related to static balance were not responsive to VR-based interventions that used dynamic balance training. Similarly, studies that used standing VR tasks failed to achieve improvements on gait-related outcomes $[38,42,44]$. However, tasks that trained walking-like activities or specific components essential for gait (ROM, strength etc.) did transfer to improved walking $[29,31,45]$. Task-specificity thus seems to be an important variable but not the only consideration in utilizing VR-based interventions.

b) Training dosage: Considerable variability was observed in total training durations that ranged from 2 to 22 hours. Although, a higher number of repetitions and longer training times are known to have beneficial effects [52], study outcomes did not seem to depend exclusively upon the training durations. In fact, a combination of task-related training and dosage may have influenced outcomes. This was also observed by Fluet et al. [18] in their recent review.

c) Feedback: VR-based interventions are inherently designed to provide rich visual feedback through the VEs. Further addition of auditory, haptic or proprioceptive inputs not only enhances engagement with the VE but also provides enriched environments for practice that may facilitate learning and underlying neuroplasticity $[52,53]$. In addition, most studies included in this review provided extrinsic feedback in the form of KP or KR. This may be especially important for learning in the post-stroke population as their intrinsic motor learning abilities may be compromised by the stroke [54]. However, the effect of this feedback on learning abilities in post-stroke individuals was not explicitly explored or reported in any study. Therefore, although it could be assumed that extrinsic feedback may have facilitated the performance, it was difficult to gauge the extent to which it may have impacted results following VR training. 
In addition to the above factors, increased motivation and engagement due to game-like nature of these interventions and variable practice provided by the interactive simulations may have also contributed to the added benefits of VR observed in this review. However, even these aspects were not adequately addressed in most studies. This review, therefore, cannot comprehensively address benefits of VR-based interventions pertaining to facilitation of motor learning and dosing parameters.

\section{VR-based interventions to promote community ambulation}

As mentioned in the earlier sections, VR can be used to create scenarios simulating real-life situations including those that simulate community environments and its challenges. This provides therapists with a unique opportunity to train patients in community scenarios but in a risk-free, graded fashion. All of the studies in this review that used treadmill walking with VR utilized VEs simulating walking in the community such as in a park or a road intersection. However, only two studies used measures that assessed transfer of training to actual community ambulation, whereas most others utilized clinical measures like gait speed and FAC that could at best be considered relevant for community ambulation. Nevertheless, positive results indicating improved abilities to navigate in the community were observed suggesting that VR-based interventions could prove to be a useful tool to train independent community ambulation. Future studies should identify this unique advantage and explore utility of VR-based training in this area though use of robust study designs and appropriate outcomes.

\section{Conclusion}

Evidence from this scoping review suggests that VRbased interventions have the potential to become an effective tool in the treatment of balance and gait deficits post stroke. However, robust study designs that identify specific objectives and choose congruent and appropriate training tasks and outcome measures need to be employed in the future to ascertain appropriate intervention and dosing parameters and achieve optimal training of balance and gait in the post-stroke population.

\section{Abbreviations}

VR: Virtual reality; VE: Virtual environment; RCT: Randomized controlled trial; TUG: Timed Up and Go; BBS: Berg balance score; CoP: Center of pressure; FAC: Functional ambulation category; ROM: Range of motion.

\section{Competing interests}

The authors declare that they have no competing interests.

\section{Authors' contributions}

AD conceptualized, designed, carried out the review and drafted the manuscript. AL and BJM helped in the critical review and drafting of the manuscript. JF helped in the conception, design, critical review and drafting of the manuscript. All authors read and approved the final manuscript.

\section{authors' information}

AD is a physiotherapist who received the Bachelors in Physiotherapy from the Maharashtra University of Health Sciences, Maharashtra, India and Masters in Physiotherapy (PT in Neurosciences) from Mumbai University, India. She is currently a PhD Candidate at the School of Physical and Occupational Therapy at McGill University in Montreal, Canada. She is a student member of the International Society of Posture and Gait Research and the International Society of Virtual Rehabilitation. Her research interests include the study of role of sensorimotor interactions in the control of locomotion in individuals with neurological deficits using biomechanical analyses and mathematical modeling and application of technology particularly virtual reality in treating gait dysfunctions caused by neurological deficits. BJM is a professor within the Department of Rehabilitation at Laval University in Quebec City, Canada and a researcher at the Center for Interdisciplinary Research in Rehabilitation and Social Integration (CIRRIS) within the Quebec Rehabilitation Institute. He is also the current president of the International Society for Posture and Gait Research. His research program is motivated by the need to understand the complex, multi-factor, systemic nature of gait and mobility in both healthy and brain injured populations. Research techniques include 3D biomechanical analyses, electrophysiology, modeling and virtual reality. AL is a researcher at Jewish Rehabilitation Hospital Site of the Centre for Interdisciplinary Research in Rehabilitation of Greater Montreal, where she leads a laboratory on Mobility and Virtual Reality. She is also Associate Professor at the School of Physical and Occupational Therapy of McGill University. She graduated from the Physiotherapy Program at Laval University (Quebec, Canada) and earned a M.Sc. and Ph.D. in Neurobiology from the same institution. Her research focuses on the visuomotor control of locomotion in older adults and persons with stroke using an approach that combines biomechanical, behavioural and perceptual experiments. JF received the professional diploma in Physiotherapy from the Hong Kong Polytechnic University in 1982. She received the Ph.D degree in Rehabilitation Science from McGill University, Montreal, Qc, Canada in 1992. She is an Associate Professor and William Dawson Scholar at the School of Physical and Occupational Therapy, McGill University. She is also director at the Feil and Oberfeld Research Centre of the Jewish Rehabilitation Hospital (site of the Montreal Centre for Interdisciplinary Research in Rehabilitation). Her research interests range from the study of basic sensorimotor integration mechanisms in the control of posture and balance, to the clinical application of new tools and technologies for the assessment and intervention of balance and mobility disorders.

\section{Acknowledgments}

We would like to thank Valérie Plante, Ėve Potvin, Laurie Thiboutot for their assistance in providing supplementary references [39] and [50]. AD received a stipend from the strategic innovative project "Rehabilitation Mall as a Living Lab" funded by the Fonds de Recherche du Québec en Santé (FRQS). $\mathrm{AL}$ and JF are members of the Sensorimotor Rehabilitation Research Team funded by the Canadian Institutes of Health Research (CIHR) http://errsm.ca/.

\section{Author details}

${ }^{1}$ School of Physical and Occupational Therapy, Faculty of Medicine, McGill University, Montreal, Quebec, Canada. ${ }^{2}$ Feil and Oberfeld Research Center, Jewish Rehabilitation Hospital, Research site of the Montreal Centre for Interdisciplinary Research in Rehabilitation (CRIR), Laval, Quebec, Canada. ${ }^{3}$ Centre for Interdisciplinary Research in Rehabilitation and Social Integration (CIRRIS) at the Quebec Rehabilitation Institute and Department of Rehabilitation, Faculty of Medicine, Laval University, Quebec, Canada.

Received: 11 August 2014 Accepted: 13 April 2015

Published online: 10 May 2015

\section{References}

1. Fang J, Alderman MH, Tu JV. Trend of stroke hospitalization, United States, 1988-1997. Stroke. 2001;32:2221-6.

2. WRITING GROUP, Lloyd-Jones D, Adams RJ, Brown TM, Carnethon M, Dai S, et al. Heart disease and stroke statistics-2010 Update: A report from the American heart Association. Circulation. 2010;121:e46-215.

3. Mayo NE, Nadeau LM, Daskalopoulous MP, Coté RM. The evolution of stroke in Quebec: A 15-year perspective. Neurology. 2007;68:1122-7.

4. Michael KM, Allen JK, Macko RF. Reduced ambulatory activity after stroke: The role of balance, gait, and cardiovascular fitness. Arch Phys Med Rehab. 2005;86:1552-6. 
5. Mayo NE, Wood-Dauphinee S, Coté R, Durcan L, Carlton J. Activity, participation, and quality of life 6 months poststroke. Arch Phys Med Rehabil. 2002;83:1035-42.

6. Lord SE, McPherson K, McNaughton HK, Rochester L, Weatherall M. Community ambulation after stroke: how important and obtainable is it and what measures appear predictive? Arch Phys Med Rehabil. 2004;85:234-9.

7. Rand D, Eng JJ, Tang PF, Jeng JS, Hung C. How active are people with stroke? Use of accelerometers to assess physical activity. Stroke. 2009;40:163-8.

8. Dean $\mathrm{CM}$, Richards $\mathrm{CL}$, Malouin F. Task-related circuit training improves performance of locomotor tasks in chronic stroke: a randomized, controlled pilot trial. Arch Phys Med Rehabil. 2000;81:409-17.

9. Rand D, Kizony R, Weiss PT. The Sony PlayStation II EyeToy: low-cost virtual reality for use in rehabilitation. J Neurol Phys Ther. 2008;32:155-63.

10. Fung J, Richards CL, Malouin F, McFadyen BJ, Lamontagne A. A treadmill and motion coupled virtual reality system for gait training post-stroke. Cyber Psychol Behav. 2006;9:157-62.

11. Rizzo AA, Schultheis M, Kerns KA, Mateer C. Analysis of assets for virtual reality applications in neuropsychology. Neuropsychol Rehabil. 2004;14:207-40.

12. Holden MK. Virtual environments for motor rehabilitation: Review. Cyberpsychol Behav. 2005:8:187-211.

13. Brummels KA, Blasius T, Cortright T, Oumedian D, Solberg B. Comparison of efficacy between traditional and video game based balance programs. Clin Kinesiol. 2008;62:26-31.

14. Schultheis MT, Rizzo AA. The application of virtual reality technology in rehabilitation. Rehabil Psychol. 2001;46:296-311.

15. Burdea GC. Virtual rehabilitation-benefits and challenges. Methods Inf Med. 2003:42:519-23.

16. Rose FD, Attree EA, Johnson DA. Virtual reality: an assistive technology in neurological rehabilitation. Curr Opin Neurol. 1996;9:461-7.

17. Crosbie JH, Lennon S, Basford JR, McDonough SM. Virtual reality in stroke rehabilitation: still more virtual than real. Disabil Rehabil. 2007;29:1139-46.

18. Fluet $\mathrm{GG}$, Deutsch JE. Virtual reality for sensorimotor rehabilitation post-stroke: the promise and current state of the field. Curr Phy Med Rehabil Reports. 2013;1:9-20.

19. Lohse KR, Hilderman CGE, Cheung KL, Van der Loos HFM. Virtual reality therapy for adults post-stroke: a systematic review and meta-analysis exploring virtual environments and commercial games in therapy. PLoS One. 2014;9, e93318.

20. Moreira MC, de Amorim Lima AM, Ferraz KM, Benedetti Rodrigues MA. Use of virtual reality in gait recovery among post stroke patients - a systematic literature review. Disabil Rehabil Assist Technol. 2013;8:357-62.

21. Laver KE, George S, Thomas S, Deutsch JE, Crotty M. Virtual reality for stroke rehabilitation. Cochrane Database Syst Rev. 2015; Art. No. CD008349 (http://dx.doi.org/10.1002/14651858.CD008349.pub3)

22. Arksey H, O'Malley L. Scoping studies: towards a methodological framework. Int J Soc Res Methodol. 2005;8:19-32.

23. Patla AE, Shumway-Cook A. Dimensions of mobility: defining the complexity and difficulty associated with community mobility. J Aging Phys Activ. 1999;7:7-19.

24. Lord SE, Rochester L. Measurement of community ambulation after stroke. Stroke. 2005;36:1457-61.

25. Perry J, Garrett M, Gronley JK, Mulroy SJ. Classification of walking handicap in the stroke population. Stroke. 1995;26:982-9.

26. Levac D, Colquhoun H, O'Brien KK. Scoping studies: advancing the methodology. Implement Sci. 2010;5:69.

27. American Academy of Cerebral Palsy and Development medicine treatment outcomes committee. AACPDM methodology to develop systematic reviews of treatment interventions (Revision 1.2). 2008. [http:// www.aacpdm.org/UserFiles/file/systematic-review-methodology.pdf]

28. Jaffe DL, Brown DA, Pierson-Carey CD, Buckley EL, Lew HL. Stepping ove obstacles to improve walking in individuals with poststroke hemiplegia. J Rehabil Res Dev. 2004:41:283-92.

29. You SH, Jang SH, Kim YH, Hallett M, Ahn SH, Kwon YH, et al. Virtual reality-induced cortical reorganization and associated locomotor recovery in chronic stroke: an experimenter-blind randomized study. Stroke. 2005;36:1166-71.

30. Yang YR, Tsai MP, Chuang TY, Sung WH, Wang RY. Virtual reality-based training improves community ambulation in individuals with stroke: a randomized controlled trial. Gait Pos. 2008;28:201-6.

31. Mirelman A, Bonato P, Deutsch JE. Effects of training with a robot-virtual reality system compared with a robot alone on the gait of individuals after stroke. Stroke. 2009:40:169-74.

32. Kim JHPP, Jang SHM, Kim CSPP, Jung JHMM, You JHP. Use of virtual reality to enhance balance and ambulation in chronic stroke: a double-blind, randomized controlled study. Am J Phys Med Rehabil. 2009;88:693-701.
33. Mirelman A, Patritti BL, Bonato P, Deutsch JE. Effects of virtual reality training on gait biomechanics of individuals post-stroke. Gait Pos. 2010;31:433-7.

34. Yang SP, Hwang WHM, Tsai YCP, Liu FKM, Hsieh LFM, Chen JSP. Improving balance skills in patients who had stroke through virtual reality treadmill training. Am J Phys Med Rehabil. 2011;90:969-78.

35. Cho KH, Lee KJ, Song $\mathrm{CH}$. Virtual-reality balance training with a video-game system improves dynamic balance in chronic stroke patients. Tohoku J Exp Med. 2012;228:69-74.

36. Cho $\mathrm{KH}$, Lee $\mathrm{WH}$. Virtual walking training program using a real-world video recording for patients with chronic stroke: a pilot study. Am J Phy Med Rehabil. 2013:92:371-84.

37. Rajaratnam BS, KaiEn JG, JiaLin L, SweeSin K, FenRu SS, Enting L, et al. Does the inclusion of virtual reality games within conventional rehabilitation enhance balance retraining after a recent episode of stroke? Rehabil Res Pract. 2013. doi:10.1155/2013/64956. 6 pages.

38. Fritz SL, Peters DM, Merlo AM, Donley J. Active video-gaming effects on balance and mobility in individuals with chronic stroke: a randomized controlled trial. Top Stroke Rehabil. 2013;20:218-25.

39. Shin WS, Lee DY, Lee SW. The effects of rehabilitation exercise using a home video game (PS2) on gait ability of chronic stroke patients. J Korea Acad Industr Coop Soc. 2010;11:368-74.

40. Jung J, Yu J, Kang $\mathrm{H}$. Effects of virtual reality treadmill training on balance and balance self-efficacy in stroke patients with a history of falling. J Phys Ther Sci. 2012;24:1133-6.

41. Kim EK, Kang JH, Park JS, Jung BH. Clinical feasibility of interactive commercial Nintendo gaming for chronic stroke rehabilitation. J Phys Ther Sci. 2012;24:901-3.

42. Singh DKA, Nordin NAM NAA, Lim BK, Soh LC. Effects of substituting a portion of standard physiotherapy time with virtual reality games among community-dwelling stroke survivors. BMC Neurol. 2013;13:199.

43. Walker ML, Ringleb SI, Maihafer GC, Walker R, Crouch JR, Van LB, et al. Virtual reality-enhanced partial body weight-supported treadmill training poststroke: feasibility and effectiveness in 6 subjects. Arch Phys Med Rehabil. 2010;91:115-22.

44. Cikajlo I, Rudolf M, Goljar N, Burger H, Matjačić Z. Telerehabilitation using virtual reality task can improve balance in patients with stroke. Disabil Rehabil. 2011:34:13-8.

45. Deutsch JE, Merians AS, Adamovich S, Poizner H, Burdea GC. Development and application of virtual reality technology to improve hand use and gait of individuals post-stroke. Restor Neurol Neurosci. 2004;22:371-86.

46. Betker AL, Szturm T, Moussavi ZK, Nett C. Video game-based exercises for balance rehabilitation: a single-subject design. Arch Phys Med Rehabil. 2006;87:1141-9.

47. Flynn S, Palma P, Bender A. Feasibility of using the Sony PlayStation 2 gaming platform for an individual poststroke: a case report. J Neurol Phys Ther. 2007:31:180-9.

48. Dunning $K$, Levine $P$, Schmitt $L$, Israel S, Fulk G. An ankle to computer virtual reality system for improving gait and function in a person 9 months post stroke. Top Stroke Rehabil. 2008;15:602-10.

49. Feasel J, Whitton MC, Kassler R, Brooks FP, Lewek MD. The integrated virtual environment rehabilitation treadmill system. IEEE Trans Neural Syst Rehabil Eng. 2011:19:290-7.

50. Lewek MD, Feasel J, Wentz E, Brooks FP, Whitton MC. Use of visual and proprioceptive feedback to improve gait speed and spatiotemporal symmetry following chronic stroke: A case series. Phys Ther. 2012;92:748-56

51. World Health Organisation: International Classification of Functioning, Disability and Health. http://apps.who.int/classifications/icfbrowser. (2001). Accessed February 6, 2015

52. Kitago T, Krakauer JW. Motor learning principles for neurorehabilitation. In: Barnes MP, Good DC, editors. Handbook of clinical neurology, vol 110. Amsterdam: Elsevier B.V; 2013. p.93-103.

53. Yu K, Wu Y, Zhang Q, Xie H, Liu G, Guo Z, et al. Enriched environment induces angiogenesis and improves neural function outcomes in a rat stroke model. J Neurol Sci. 2014;347:275-80.

54. Van Vliet PM, Wulf G. Extrinsic feedback for motor learning after stroke: What is the evidence? Disabil Rehabil. 2006;28:831-40. 